\title{
Densities and Viscosities of the Ternary Mixtures Water + Butyl Acetate + Methanol and Water + Ethyl Propionate + Methanol at $303.15 \mathrm{~K}$
}

\author{
Zoran P. Visak, Abel G. M. Ferreira, and Isabel M. A. Fonseca* \\ Faculty of Technology and Metallurgy, University of Belgrade, Belgrade, Yugoslavia, \\ and Department of Chemical Engineering, University of Coimbra, Coimbra, Portugal
}

\begin{abstract}
The excess molar volumes, $\mathrm{V}^{\mathrm{E}}$, and viscosity deviations, $\Delta \eta$, were calculated from the measured density and viscosity values over the whole miscibility composition ranges for the ternary systems water + butyl acetate + methanol and water + ethyl propionate + methanol and their constituent binaries, at $303.15 \mathrm{~K}$ and atmospheric pressure. A Redlich-Kister type equation was used to correlate binary VE and $\Delta \eta$ data, as well as the ternary data. This equation was used to cal culate the above referred properties along the binodal curve.
\end{abstract}

\section{Introduction}

Rao and Rao determined the solubility curves and tie line data for liquid systems of the type water + ester + methanol ${ }^{1}$ and water + ester + propan-1-ol ${ }^{2}$ at $303.15 \mathrm{~K}$. The aim of this research was to find a suitable solvent for the extraction of the alcohols from their aqueous solutions. I ndeed, for a conventional liquid-liquid extraction (i.e. not supercritical) the right selection of the solvent is the key to a successful separation. On the other hand, the knowledge of the density and the viscosity of multicomponent systems is essential in many industrial applications.

The mixture functions, such as the excess molar volume, $\mathrm{VE}$, and viscosity deviations, $\Delta \eta$, are often used to describe the intermolecular forces in mixtures, helping us to understand their real behavior and develop models for its description.

The cited references have suggested to us a systematic study of densities and excess volumes, viscosities, and viscosity deviations, involving the ternary mixtures mentioned above. In a previous paper, ${ }^{3}$ we have reported densities and $V^{E}$ values for the system water + propyl acetate + propan-1-ol at $303.15 \mathrm{~K}$. In the present work we have determined densities, excess molar volumes, viscosities, and viscosity deviations for theternaries water + butyl acetate + methanol and water + ethyl propionate + methanol, at the same temperature.

\section{Experimental Section}

Materials. Tridistilled water was used. Methanol was supplied by Fluka AG and Lab-Scan with a purity $>99.8$ mass \% (HPLC grade). Ethyl propionate was supplied by Riedel de Haen, while butyl acetate was from Aldrich, both with purity > 99 mass \%. Table 1 lists the measured densities and viscosities of the alcohol and of the two esters together with the values found in the literature. Since the agreement is good, and having in mind that small concentrations of impurities have little influence on the excess

* To whom correspondence should be addressed at the University of Coimbra. Telephone: + 351-239 798729. Fax: + 351-239 798703. E-mail: fonseca@eq.uc.pt.
Table 1. Densities, $\rho /\left(\mathrm{g} \mathrm{cm}^{-3}\right)$, and Viscosities, $\eta /(\mathrm{mPa} s)$, of the Pure Components at $303.15 \mathrm{~K}$

\begin{tabular}{lccccc}
\hline \multirow{2}{*}{ component } & \multicolumn{2}{c}{$\rho$} & & \multicolumn{2}{c}{$\eta$} \\
\cline { 2 - 3 } water & exptl & lit. & & exptl & lit. \\
methanol & \multirow{2}{*}{0.78199} & $0.99570^{4}$ & & $0.797^{8}$ \\
& & $0.78186^{5}$ & & 0.516 & $0.510^{6}$ \\
& & $0.78200^{1}$ & & $0.503^{10}$ \\
butyl acetate & 0.87120 & $0.87123^{7}$ & & 0.631 & $0.636^{11}$ \\
& & $0.87100^{1}$ & & $0.623^{12}$ \\
ethyl propionate & 0.87887 & $0.87900^{1}$ & 0.494 & $0.474^{11}$
\end{tabular}

molar volumes, ${ }^{13}$ all the compounds were used without further purification. Mixtures were prepared by mass using a Mettler AT 200 balance with a precision of $\pm 10^{-5} \mathrm{~g}$.

Measurements. Densities were measured in an Anton Paar DMA 60 digital vibrating tube densimeter, with a DMA 602 measuring cell. Air and tridistilled water were used for the calibration of the densimeter. Viscosities were obtained with a Haake Falling Ball Viscosimeter (Hoppler design), calibrated with tridistilled water. The electronic digital stopwatch, with the uncertainty $\pm 0.01 \mathrm{~s}$, was used to measure the falling time of the ball. In all the measurements, the temperature maintenance and control were performed using the Haake D8-G thermostatic water bath, which has a temperature precision of $\pm 0.01 \mathrm{~K}$. In the case of density measurements, the $\mathrm{Pt}$ resistance thermometer (calibrated against a precision mercury thermometer, graduated in $0.01{ }^{\circ} \mathrm{C}$, certified by NPL, U.K.) was placed inside the vibrating tube densimeter to find the actual temperature of the measurements. The temperature was maintained at $(303.15 \pm 0.01) \mathrm{K}$.

Uncertainties. Densities were measured to a precision of $10^{-5} \mathrm{~g} \mathrm{~cm}^{-3}$. Having in mind that the error in the excess molar volume, $\mathrm{VE}$, is determined by the uncertainties in mole fraction and density, the maximum error in $V E$ resulting from the propagation law of errors is $5 \times 10^{-3}$ $\mathrm{cm}^{3} \mathrm{~mol}^{-1}$. Using a similar methodology and taking into consideration the uncertainties in the measured time and in the density, the experimental uncertainty in the viscosity is $\pm 0.001 \mathrm{mPa}$ s. 
Table 2. Densities, $\rho /\left(\mathrm{g} \mathrm{cm}^{-3}\right)$, and Excess Molar Volumes, $\mathrm{VE} /\left(\mathrm{cm}^{3} \mathbf{~ m o l}^{-1}\right)$, for the System Water (1) + Butyl Acetate (2) + Methanol (3) and Its Binary Constituents, at $303.15 \mathrm{~K}$ and Atmospheric Pressure

\begin{tabular}{|c|c|c|c|c|c|c|c|}
\hline$x_{1}$ & $x_{2}$ & $\rho$ & VE & $x_{1}$ & $x_{2}$ & $\rho$ & VE \\
\hline 0273 & 0.1466 & 0.81783 & -0.101 & 0.1998 & 0 & 0.81741 & -0.6 \\
\hline & & & -0.079 & 0.2055 & 0 & 0.81852 & \\
\hline & 0.7744 & 0.86623 & -0.067 & 0.2273 & 0 & 0.82248 & \\
\hline & 0.2836 & 0.83791 & -0.151 & 0.2526 & 0 & 0.82732 & -0 . \\
\hline 499 & 0.3445 & 0.84352 & -0.140 & 0.2777 & 0 & 0.83233 & -0. \\
\hline 522 & 0.0545 & 0.80405 & -0.172 & 0.2985 & 0 & 0.83642 & -0.8 \\
\hline 0.0550 & 0.4728 & 0.85315 & -0.114 & 0.3014 & 0 & 0.83697 & \\
\hline 0.0632 & 0.7524 & 0.86714 & -0.103 & 0.3532 & 0 & 0.84700 & -0.9 \\
\hline 893 & 0.5807 & 0.86194 & -0.172 & 0.4013 & 0 & 0.85706 & -0.9 \\
\hline 0.1204 & 0.4400 & 0.85676 & -0.230 & 0.4042 & 0 & 0.85732 & -0.9 \\
\hline & 0. & 0.8 & -0.383 & 0.4 & 0 & & \\
\hline 0.1409 & 0.3115 & 0.85003 & -0.325 & 0.4824 & 0 & 0.87361 & -1.0 \\
\hline 0 & 0.544 & 0.8 & -0.265 & 0.4 & 0 & 0.8 & -1 \\
\hline 3 & 0.04 & 0.8 & -0.460 & 0.5 & 0 & 0.8 & -0 . \\
\hline 1 & 0.250 & 0.8 & -0.388 & 0.5 & 0 & 0.8 & \\
\hline & 0.5 & 0.86 & -0.303 & 0.6500 & 0 & 0.9 & -0 \\
\hline & 0.2973 & 0.85305 & -0.396 & $0.6 \mathrm{~s}$ & 0 & 0.9 & -0 \\
\hline & 0.3971 & 0.86 & -0.370 & 0.7 & 0 & 0.92587 & -0.8 \\
\hline 9 & 0.2804 & 89 & -0.476 & 0.75 & 0 & 324 & $-c$ \\
\hline 439 & 0.1139 & 0.8 & -0.612 & 0.7 & 0 & 846 & -0 \\
\hline 0. & 0.0432 & 0.83412 & -0.685 & 0.7734 & 0 & 0.93858 & -0 \\
\hline 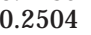 & 0.2719 & 0.8 & -0.515 & 0.8 & 0 & 714 & $-c$ \\
\hline 52 & 0.3741 & 0.86515 & -0.434 & 0.85 & 0 & 613 & -0.4 \\
\hline 1 & 0.222 & & -0.5 & 0.8 & 0 & 0. & -0 \\
\hline 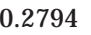 & 0.2614 & 0.8 & -0.554 & 0.9198 & 0 & 0.9 & \\
\hline 0.2 & 0.35 & 0.8 & -0.489 & 0 & 0.0575 & 697 & -00 \\
\hline & $0.24 \mathrm{~S}$ & & -0.5 & 0 & & & -0 \\
\hline & 0.0374 & & -0.849 & 0 & 0.2 & 0.8 & -0 \\
\hline & 0.2 & & -0.6 & 0 & 0.2 & & \\
\hline & 0.09 & & -0.7 & 0 & 0.3 & 21 & \\
\hline & 0.22 & & -0. & 0 & 0.5 & & \\
\hline & 0.0316 & 0.86 & -0.940 & 0 & 0.6 & 0.85801 & \\
\hline & & & -0.8 & 0 & & & \\
\hline 0. & 0.0690 & 0.88 & -0.882 & 0 & 0.80 & 0.86511 & -0.0 \\
\hline & 0.0260 & 0.88835 & -0.956 & 0 & 0.9201 & 0.86988 & \\
\hline & 0.021 & 0.96 & -0.915 & & & & \\
\hline & & & -0.170 & & & & \\
\hline & 0 & & & & & & \\
\hline & 0 & 0.8 & -0 . & & & & \\
\hline & 0 & 23 & -0.5 & & & & \\
\hline
\end{tabular}

\section{Results and Discussion}

The excess molar volumes, $\mathrm{V}^{\mathrm{E}}$, were calculated from the equation

$$
\mathrm{V}^{\mathrm{E}}=\rho^{-1}\left(\sum \mathrm{x}_{\mathrm{i}} \mathrm{M}_{\mathrm{i}}\right)-\sum \mathrm{X}_{\mathrm{i}} \mathrm{M}_{\mathrm{i}} \rho_{\mathrm{i}}^{-1}
$$

where $x_{i}$ is the mole fraction of component $i$ in the mixture, $M_{i}$ is its molecular weight, and $\rho$ and $\rho_{\mathrm{i}}$ are the measured densities of the mixture and the pure component, respectively.

The calculation of the dynamic viscosity is done according to the formula

$$
\eta=\mathrm{K}\left(\rho_{\mathrm{b}}-\rho\right) \mathrm{t}
$$

where $t$ is the falling time of the ball measured with the stopwatch. $\mathrm{K}$ is a calibration constant, and $\rho_{\mathrm{b}}$ and $\rho$ represent the densities of the ball and the liquid, respectively.

The viscosity deviations, $\Delta \eta$, were obtained using the expression

$$
\Delta \eta=\eta-\sum \mathrm{x}_{\mathrm{i}} \eta_{\mathrm{i}}
$$

where $\eta$ is the measured mixture viscosity and $\eta_{\mathrm{i}}$ represents the pure component viscosity. The viscosity measurements were made for different compositions than those for the density measurements, since they were not performed simultaneously. For that reason, the density value needed to obtain the viscosity by eq 2 was calculated with eq 1 .
Table 3. Densities, $\rho /\left(\mathrm{g} \mathrm{cm}^{-3}\right)$, and Excess Molar Volumes, $\mathrm{VE} /\left(\mathrm{cm}^{3} \mathrm{~mol}^{-1}\right)$, for the System Water (1) + Ethyl Propionate (2) + Methanol (3) and Its Binary Constituents, at 303.15 K and Atmospheric Pressure

$\begin{array}{cccccccc}\mathrm{x}_{1} & \mathrm{x}_{2} & \rho & \mathrm{VE} & \mathrm{x}_{1} & \mathrm{x}_{2} & \rho & \mathrm{VE}\end{array}$

\begin{tabular}{llllllll}
\hline 0.0428 & 0.6726 & 0.86859 & -0.124 & 0.3110 & 0.1031 & 0.85524 & -0.802
\end{tabular}

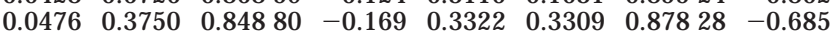

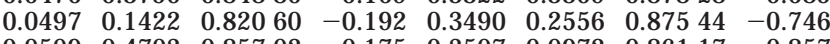

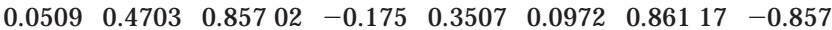
$\begin{array}{lllllllll}0.0510 & 0.0476 & 0.80231 & -0.186 & 0.3514 & 0.0657 & 0.857 & 05 & -0.870\end{array}$

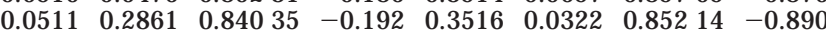

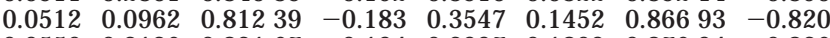
$\begin{array}{llllllllll}0.0550 & 0.2126 & 0.831 & 67 & -0.194 & 0.3997 & 0.1809 & 0.876 & 94 & -0.836\end{array}$ $\begin{array}{llllllllll}0.0976 & 0.7219 & 0.875 & 31 & -0.205 & 0.4002 & 0.1349 & 0.873 & 22 & -0.874\end{array}$ $\begin{array}{lllllllll}0.0986 & 0.0452 & 0.80964 & -0.340 & 0.4009 & 0.0298 & 0.861 & 23 & -0.944\end{array}$

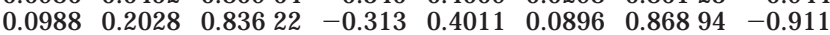
$\begin{array}{lllllllll}0.0997 & 0.3545 & 0.85276 & -0.293 & 0.4012 & 0.0607 & 0.865 & 40 & -0.924\end{array}$

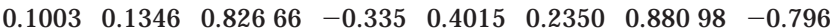

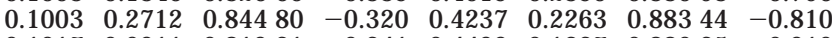

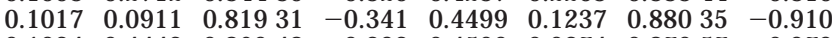

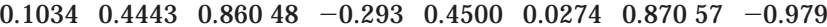
$\begin{array}{lllllllll}0.1080 & 0.5389 & 0.867 & 25 & -0.295 & 0.4500 & 0.0558 & 0.87387 & -0.960\end{array}$ $\begin{array}{lllllllll}0.1086 & 0.6264 & 0.871 & 83 & -0.253 & 0.4502 & 0.0823 & 0.87656 & -0.936\end{array}$ $\begin{array}{lllllllll}0.1444 & 0.6012 & 0.87375 & -0.321 & 0.4526 & 0.1650 & 0.88373 & -0.873\end{array}$



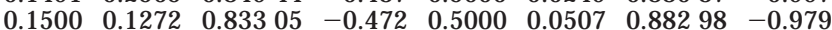
$\begin{array}{llllllllll}0.1501 & 0.0862 & 0.826 & 16 & -0.477 & 0.5000 & 0.0748 & 0.885 & 01 & -0.958\end{array}$ $\begin{array}{lllllllll}0.1503 & 0.3346 & 0.85690 & -0.408 & 0.5012 & 0.1122 & 0.888 & 08 & -0.930\end{array}$

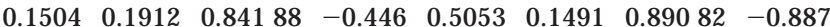

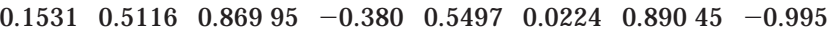

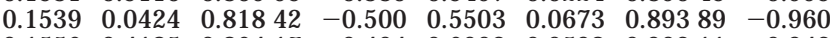

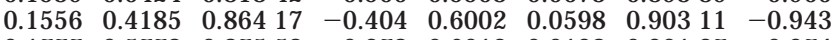

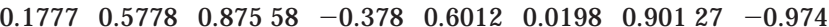

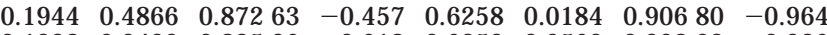

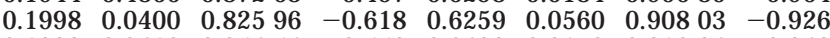



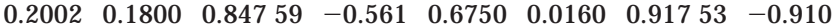

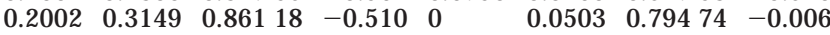

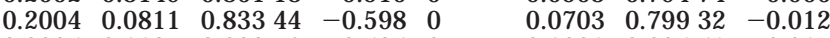

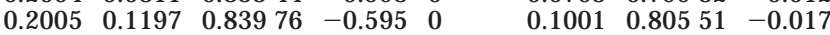

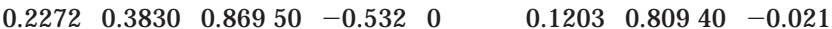
$\begin{array}{llllllllll}0.2464 & 0.4553 & 0.876 & 13 & -0.540 & 0 & & 0.1479 & 0.81431 & -0.023\end{array}$ $\begin{array}{llllllllll}0.2495 & 0.1689 & 0.85346 & -0.660 & 0 & & 0.1734 & 0.81860 & -0.031\end{array}$ $\begin{array}{lllllllll}0.2505 & 0.2259 & 0.85981 & -0.644 & 0 & & 0.2505 & 0.82975 & -0.040\end{array}$ $\begin{array}{lllllllllll}0.2511 & 0.2949 & 0.86584 & -0.605 & 0 & & 0.4031 & 0.84634 & -0.055\end{array}$

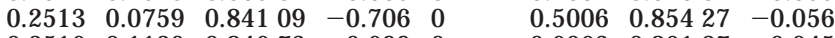

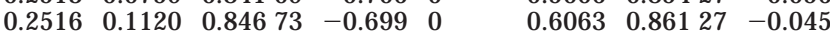

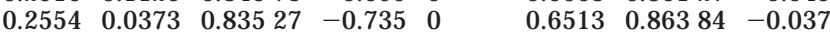

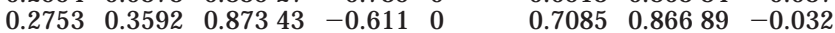


$\begin{array}{lllllllllll}0.3001 & 0.0348 & 0.84288 & -0.808 & 0 & & 0.7722 & 0.869 & 74 & -0.022\end{array}$

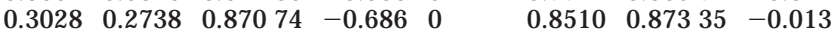
$\begin{array}{llll}0.3099 & 0.0700 & 0.85029 & -0.811\end{array}$

Table 4. Viscosities, $\eta /(\mathrm{mPa})$, and Viscosity Deviations, $\Delta \eta /(\mathrm{mPa}$ s), for the System Water (1) + Butyl Acetate (2) + Methanol (3) and Its Binary Constituents, at 303.15 K and Atmospheric Pressure

\begin{tabular}{cccccccc}
\hline $\mathrm{x}_{1}$ & $\mathrm{x}_{2}$ & $\eta$ & $\Delta \eta$ & $\mathrm{x}_{1}$ & \multicolumn{1}{c}{$\mathrm{x}_{2}$} & $\eta$ & $\Delta \eta$ \\
\hline 0.1081 & 0.2745 & 0.649 & 0.071 & 0.1232 & 0 & 0.625 & 0.074 \\
0.1853 & 0.2501 & 0.709 & 0.112 & 0.1599 & 0 & 0.679 & 0.118 \\
0.2411 & 0.2336 & 0.776 & 0.165 & 0.2168 & 0 & 0.765 & 0.188 \\
0.3114 & 0.2119 & 0.845 & 0.217 & 0.2992 & 0 & 0.874 & 0.274 \\
0.4010 & 0.1843 & 0.921 & 0.271 & 0.3639 & 0 & 0.972 & 0.354 \\
0.0936 & 0.4363 & 0.657 & 0.061 & 0.3948 & 0 & 1.021 & 0.394 \\
0.1699 & 0.4305 & 0.698 & 0.110 & 0.4567 & 0 & 1.129 & 0.485 \\
0.2025 & 0.3839 & 0.711 & 0.128 & 0.5837 & 0 & 1.310 & 0.630 \\
0.2732 & 0.3770 & 0.776 & 0.140 & 0.8272 & 0 & 1.319 & 0.571 \\
0.0200 & 0.1967 & 0.563 & 0.019 & 0.8782 & 0 & 1.213 & 0.450 \\
0.0785 & 0.1850 & 0.628 & 0.069 & 0.8860 & 0 & 1.185 & 0.420 \\
0.0511 & 0.0752 & 0.574 & 0.035 & 0.9125 & 0 & 1.110 & 0.349 \\
0.0806 & 0.0728 & 0.602 & 0.055 & 0 & 0.0963 & 0.528 & 0.001 \\
0.2189 & 0.0619 & 0.735 & 0.150 & 0 & 0.1331 & 0.533 & 0.002 \\
0.3238 & 0.0536 & 0.855 & 0.242 & 0 & 0.1759 & 0.539 & 0.003 \\
0.0673 & 0.1624 & 0.608 & 0.054 & 0 & 0.2825 & 0.552 & 0.004 \\
0.1631 & 0.1457 & 0.704 & 0.125 & 0 & 0.3931 & 0.566 & 0.005 \\
0.3747 & 0.1089 & 0.978 & 0.344 & 0 & 0.4804 & 0.577 & 0.006 \\
0.0773 & 0.1859 & 0.621 & 0.062 & 0 & 0.5458 & 0.585 & 0.006 \\
0.1672 & 0.1678 & 0.699 & 0.117 & 0 & 0.6116 & 0.592 & 0.006 \\
0.1519 & 0.3474 & 0.725 & 0.126 & 0 & 0.6478 & 0.596 & 0.006 \\
0.2511 & 0.3068 & 0.784 & 0.162 & 0 & 0.7391 & 0.606 & 0.005 \\
0.0892 & 0.3823 & 0.667 & 0.082 & 0 & 0.8007 & 0.612 & 0.004 \\
0.1313 & 0.3646 & 0.705 & 0.110 & 0 & 0.8409 & 0.616 & 0.003 \\
0.1242 & 0.5228 & 0.634 & 0.095 & 0 & 0.8858 & 0.621 & 0.003 \\
0.1510 & 0.5067 & 0.665 & 0.118 & 0 & 0.9240 & 0.624 & 0.002 \\
0.0804 & 0.6256 & 0.591 & 0.066 & & & &
\end{tabular}


928 J ournal of Chemical and Engineering Data, Vol. 45, No. 5, 2000

Table 5. Viscosities, $\eta /(\mathrm{mPa})$, and Viscosity Deviations, $\Delta \eta /(\mathrm{mPa}$ s), for the System Water (1) + Ethyl Propionate (2) + Methanol (3) and Its Binary Constituents, at 303.15 K and Atmospheric Pressure

\begin{tabular}{cccccccc}
\hline $\mathrm{x}_{1}$ & $\mathrm{x}_{2}$ & $\eta$ & $\Delta \eta$ & $\mathrm{x}_{1}$ & $\mathrm{x}_{2}$ & $\eta$ & $\Delta \eta$ \\
\hline 0.2875 & 0.1830 & 0.769 & 0.176 & 0 & 0.1102 & 0.524 & 0.010 \\
0.4750 & 0.1649 & 1.016 & 0.370 & 0 & 0.1551 & 0.525 & 0.012 \\
0.0830 & 0.2343 & 0.560 & 0.026 & 0 & 0.2735 & 0.526 & 0.016 \\
0.1337 & 0.2329 & 0.589 & 0.041 & 0 & 0.3189 & 0.527 & 0.018 \\
0.0650 & 0.1491 & 0.568 & 0.037 & 0 & 0.3721 & 0.528 & 0.020 \\
0.1094 & 0.1447 & 0.608 & 0.064 & 0 & 0.4967 & 0.527 & 0.022 \\
0.1512 & 0.1301 & 0.652 & 0.096 & 0 & 0.5395 & 0.524 & 0.020 \\
0.2028 & 0.1265 & 0.727 & 0.157 & 0 & 0.6130 & 0.521 & 0.019 \\
0.2551 & 0.1160 & 0.758 & 0.173 & 0 & 0.6625 & 0.518 & 0.017 \\
0.2242 & 0.3689 & 0.629 & 0.058 & 0 & 0.7231 & 0.514 & 0.014 \\
0.1118 & 0.4561 & 0.565 & 0.028 & 0 & 0.8087 & 0.508 & 0.010 \\
0.1403 & 0.3921 & 0.601 & 0.054 & 0 & 0.9141 & 0.501 & 0.005 \\
0.0911 & 0.3734 & 0.590 & 0.057 & & & & \\
0.1302 & 0.3507 & 0.606 & 0.061 & & & & \\
0.1248 & 0.5418 & 0.622 & 0.083 & & & & \\
0.0531 & 0.5918 & 0.553 & 0.035 & & & & \\
0.1152 & 0.6309 & 0.594 & 0.060 & & & & \\
0.0531 & 0.6649 & 0.565 & 0.049 & & & & \\
0.0587 & 0.7049 & 0.568 & 0.115 & & & & \\
0.2542 & 0.3066 & 0.736 & 0.155 & & & &
\end{tabular}

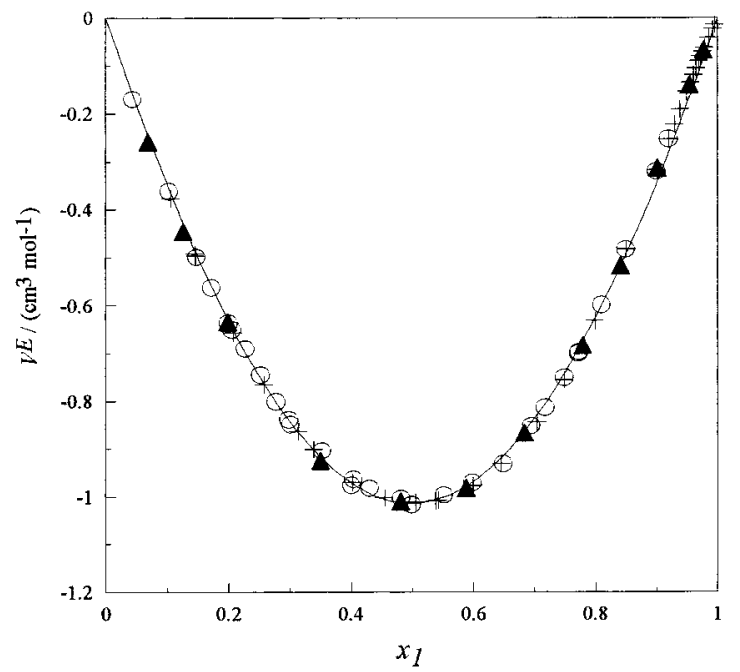

Figure 1. $V^{E}$ of water (1) + methanol (3) as a function of mole fraction of water: $(O)$ this work; $(+)$ Benson and Kiyohara; ${ }^{14}(\mathbf{\Lambda})$ Dizechi and Marschall. ${ }^{4}$

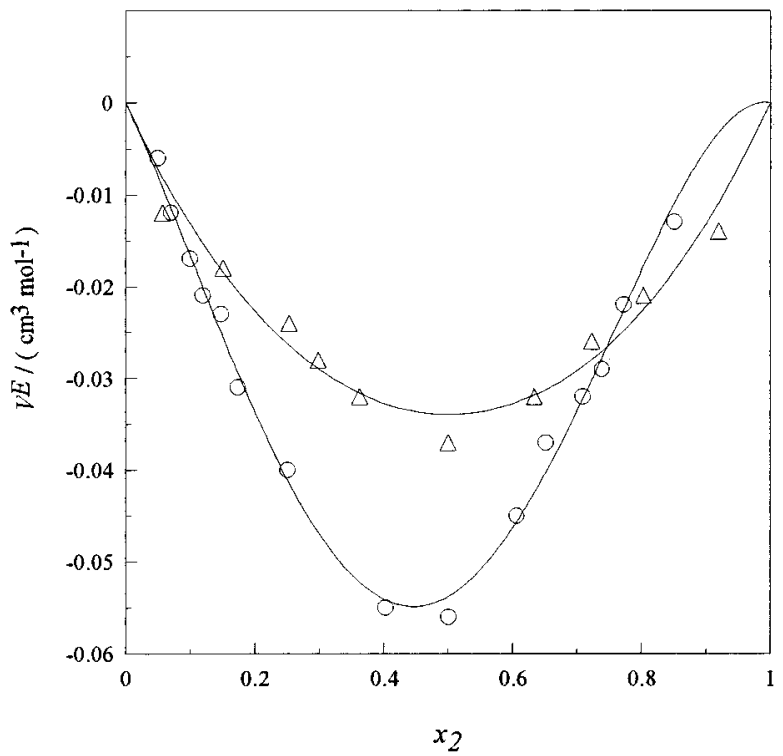

Figure 2. Excess molar volumes, $\mathrm{VE}$, of methanol + ester as a function of mole fraction of the ester, $x_{2}$, at $303.15 \mathrm{~K}$ and atmospheric pressure: $(\Delta)$ butyl acetate; $(O)$ ethyl propionate.

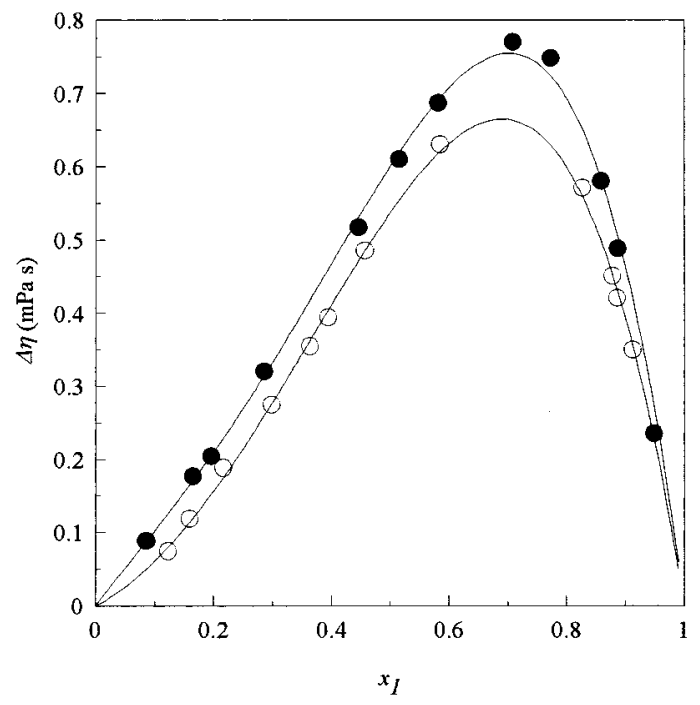

Figure 3. Viscosity departures, $\Delta \eta$, of water + methanol as a function of mole fraction of water, $x_{1}$, at atmospheric pressure: (○) this work, at $303.15 \mathrm{~K}$; (•) Noda et al., ${ }^{16}$ at $298.15 \mathrm{~K}$.

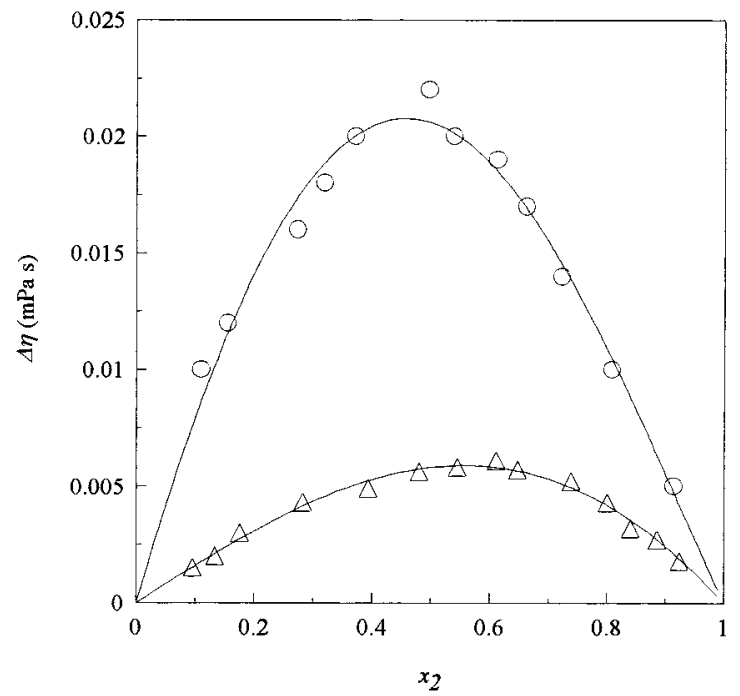

Figure 4. Viscosity departures, $\Delta \eta$, of ester + methanol as a function of mole fraction of the ester, $x_{2}$, at $303.15 \mathrm{~K}$ and atmospheric pressure: $(\Delta)$ butyl acetate; $(O)$ ethyl propionate.

Tables 2 and 3 list the measured densities, $\rho$, and the corresponding values of $\mathrm{VE}$ for the two ternary systems, whereas Tables 4 and 5 present the measured viscosities, $\eta$, and the corresponding $\Delta \eta$ values for the same ternaries. Results for the constituent binaries water (1) + methanol (3) and ester (2) + methanol (3) are al so included.

In Figure 1 we have plotted the experimental VE values for the binary water (1) + methanol (3) measured by several authors together with our own, which shows a good agreement. The experimental $\mathrm{VE}$ values for the binaries ester (2) + methanol (3) are represented against the mole fraction of the ester in Figure 2. As far as we know, these values have not been published before.

We have not found in the literature any binary viscosity data at $303.15 \mathrm{~K}$ for the system water (1) + methanol (3). The only values available in the literature are for 298.15 K. In Figure 3 we compare our measured $\Delta \eta$ values at $303.15 \mathrm{~K}$ with the data from the literature at $298.15 \mathrm{~K}$. As we can see, both sets of points show the same trend. In Figure 4 we have presented the experimental $\Delta \eta$ values for the binaries ester (2) + methanol (3) as a function of the mole fraction of the ester. We have not found 


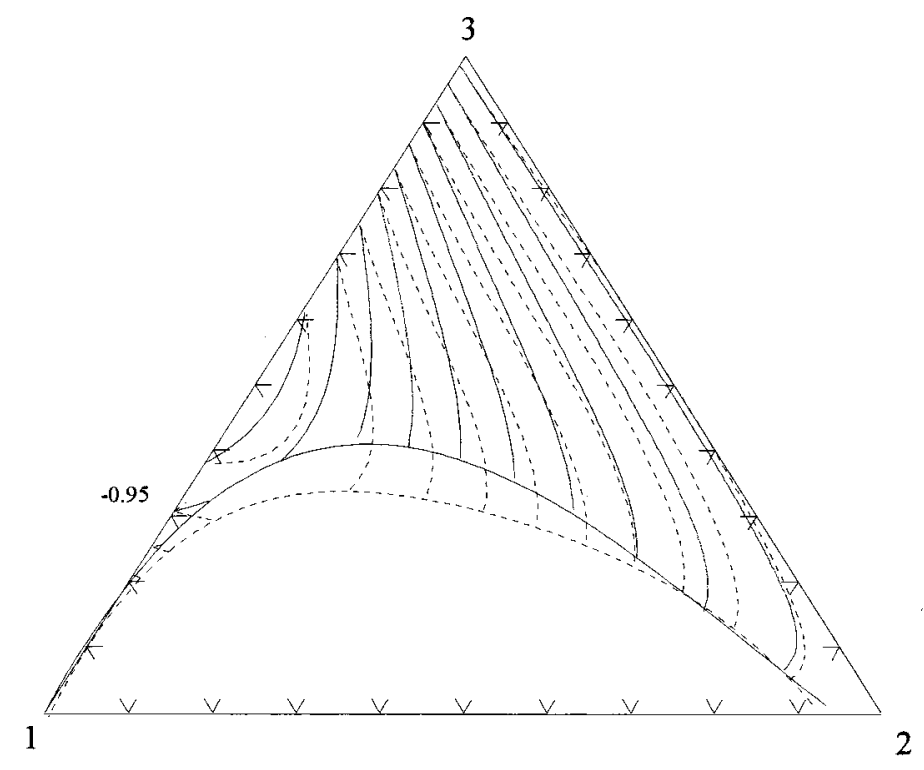

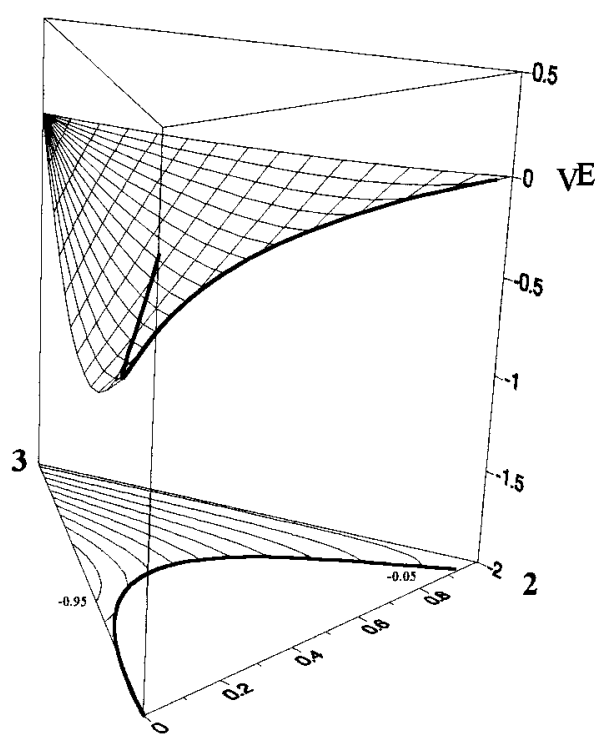

water(1)+butyl acetate(2) +methanol(3)



water(1) + ethyl propionate(2) + methanol(3)

Figure 5. Excess molar volume isolines and perspective views of $\mathrm{VE}^{\mathrm{E}}\left(\mathrm{cm}^{3} \mathrm{~mol}^{-1}\right)$ for water (1) + butyl actate (2) + methanol (3) $(-)$ and water (1) + ethyl propionate (2) + methanol (3) (- - ) at $303.15 \mathrm{~K}$ and atmospheric pressure. The increment of $\mathrm{VE}^{\mathrm{E}}$ is $0.1 \mathrm{~cm}^{3} \mathrm{~mol}^{-1}$.

in the literature any $\Delta \eta$ experimental values for these systems.

The $\mathrm{VE}$ and $\Delta \eta$ binary data were correlated using a Redlich-Kister type equation for the binary systems: ${ }^{15}$

$$
x_{i j}=x_{i} x_{j} \sum A_{k}\left(x_{i}-x_{j}\right)^{k} \quad k=0,1,2, \ldots, n
$$

where $\mathrm{X}$ represents $\mathrm{VE}^{\mathrm{E}}$ and $\Delta \eta$.

The ternary data ( $\mathrm{V}^{\mathrm{E}}$ and $\Delta \eta$ ) were correlated by a Redlich-Kister type equation for the ternaries: ${ }^{15}$

$$
\begin{array}{r}
X_{123}=X_{12}+X_{23}+X_{13}+x_{1} x_{2} x_{3}\left[A+B_{1}\left(x_{1}-x_{2}\right)+\right. \\
\left.B_{2}\left(x_{2}-x_{3}\right)\right]
\end{array}
$$

where $\mathrm{X}_{123}$ represents the excess molar volume and the viscosity data for the ternary system and $X_{i j}$ are the values of the Redlich-Kister polynomial for the same properties, obtained by fitting eq 4 to the binary data.
Several authors have used the Cibulka's equation, ${ }^{17}$

$$
\begin{array}{r}
\Delta \eta_{123}=\Delta \eta_{12}+\Delta \eta_{13}+\Delta \eta_{23}+ \\
\mathrm{x}_{1} \mathrm{x}_{2} \mathrm{x}_{3}\left(\mathrm{C}_{0}+\mathrm{C}_{1} \mathrm{x}_{1}+\mathrm{C}_{2} \mathrm{x}_{2}\right)
\end{array}
$$

to describe the ternary $\Delta \eta$ data, where the terms have a similar meaning as in eq 5 . This equation differs from the Redlich-Kister one in the form of the ternary contribution. However, both forms are equival ent, since their coefficients are related by the following expressions

$$
\mathrm{C}_{0}=\mathrm{A}-\mathrm{B}_{2}, \quad \mathrm{C}_{1}=\mathrm{B}_{1}+\mathrm{B}_{2}, \quad \text { and } \mathrm{C}_{2}=2 \mathrm{~B}_{2}-\mathrm{B}_{1}
$$

Thus, to be consistent, we decided to treat all the experimental data with the Redlich-Kister equation.

The standard deviation, $\sigma$, of the fittings is defined as

$$
\sigma=\left[\sum\left(\mathrm{X}_{\exp }-\mathrm{X}_{\text {calc }}\right)^{2} /(\mathrm{M}-\mathrm{n})\right]^{1 / 2}
$$




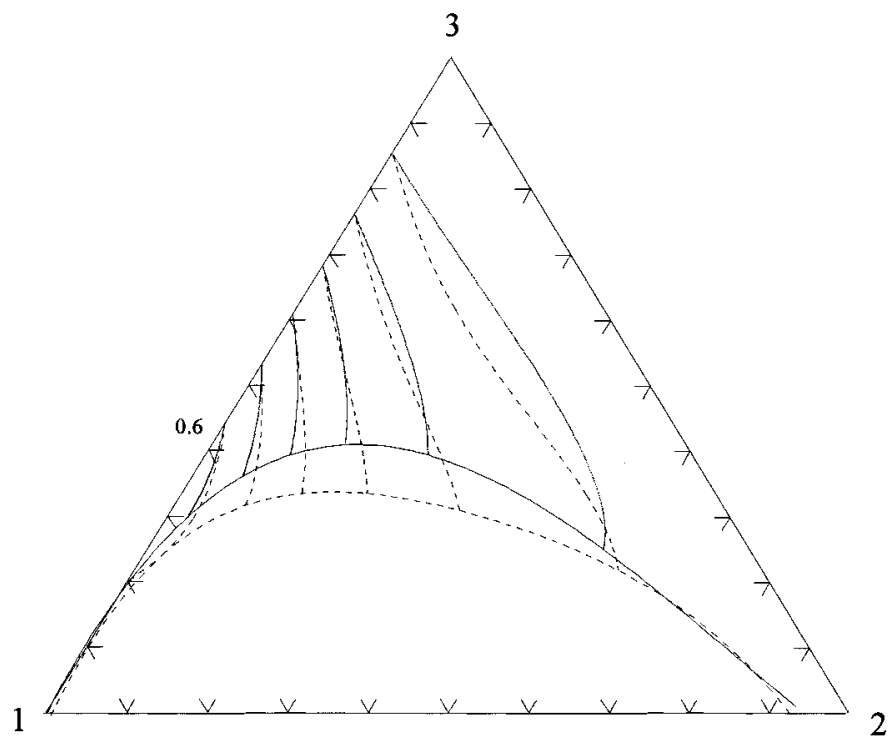



water(1)+butyl acetate(2)+methanol(3)

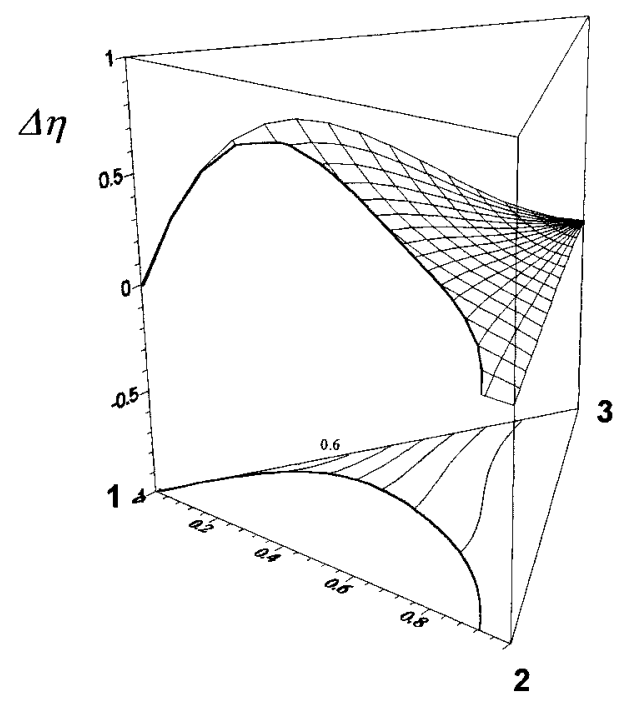

water(1)+ethyl propionate(2)+methanol(3)

Figure 6. I solines and perspective views of $\Delta \eta(\mathrm{mPa} \mathrm{s})$ for water $(1)+$ butyl acetate $(2)+$ methanol (3) $(-)$ and water (1) + ethyl propionate (2) + methanol (3) (- - ) at $303.15 \mathrm{~K}$ and atmospheric pressure. The increment of $\Delta \eta$ is $(-0.1) \mathrm{mPa} \mathrm{s}$.

Table 6. Coefficients of Eq 4 Fitted to the Excess Volume, $\mathrm{VE}^{\mathrm{E}} /\left(\mathrm{cm}^{3} \mathrm{~mol}^{-1}\right)$, and Viscosity Deviation, $\Delta \eta /(\mathrm{mPa})$, for the Binary Systems ${ }^{\mathrm{a}}$

\begin{tabular}{lccrrr}
\hline \multicolumn{1}{c}{ system } & property & \multicolumn{1}{c}{$\mathrm{A}_{0}$} & \multicolumn{1}{c}{$\mathrm{A}_{1}$} & \multicolumn{1}{c}{$\mathrm{A}_{2}$} & $\sigma$ \\
\hline water + methanol & $\mathrm{V} E$ & -4.053 & 0.024 & 0.316 & 0.012 \\
butyl acetate + methanol & & -0.136 & -0.001 & -0.018 & 0.003 \\
ethyl propionate + & & -0.215 & 0.080 & 0.146 & 0.002 \\
$\quad$ methanol & $\Delta \eta$ & 2.149 & 2.308 & 0.578 & 0.010 \\
water + methanol & & 0.023 & 0.006 & & 0.001 \\
butyl acetate+ methanol & & 0.081 & -0.016 & & 0.001 \\
ethyl propionate + & & & & &
\end{tabular}
methanol

a The value of the standard deviation, $\sigma$, and the parameters are expressed in the units of the related property.

where $\mathrm{X}$ is $\mathrm{VE}$ or $\Delta \eta$ and $\mathrm{M}$ and $\mathrm{n}$ represent the numbers of the experimental points and parameters, respectively.

The optimized coefficients, $A_{k}$, and the standard deviations, $\sigma$, for binary $\mathrm{VE}$ and $\Delta \eta$ data are listed in Table 6. $\mathrm{V}_{12}{ }^{\mathrm{E}}$ and $\Delta \eta_{12}$ are taken to be identically zero, since water and the ester are practically immiscible. The coefficients $A$ and $B_{i}$ of eq 5 and the standard deviations of the corresponding fittings are given in Table 7.
Table 7. Coefficients of Eq 5 Fitted to the Excess Volume, $V^{E} /\left(\mathrm{cm}^{3} \mathrm{~mol}^{-1}\right)$, and Viscosity Deviation, $\Delta \eta /$ (mPa s), for the Ternary Systems ${ }^{a}$

\begin{tabular}{lccccc}
\hline \multicolumn{1}{c}{ ester } & property & $\mathrm{A}$ & $\mathrm{B}_{1}$ & $\mathrm{~B}_{2}$ & $\sigma$ \\
\hline butyl acetate & $\mathrm{V}$ & -1.805 & -3.949 & -6.801 & 0.010 \\
ethyl propionate & & -5.824 & -6.931 & -9.537 & 0.015 \\
butyl acetate & $\Delta \eta$ & -1.669 & -6.742 & -2.302 & 0.015 \\
ethyl propionate & & -1.140 & -0.764 & 3.129 & 0.024
\end{tabular}

a The value of the standard deviation, $\sigma$, and the parameters are expressed in the units of the related property.

In Figures 5 and 6 are shown the isolines and the perspective views of the excess molar volumes and the viscosity deviations for the ternary systems.

\section{Conclusions}

The determined values of the excess molar volumes for the binaries and ternaries at $303.15 \mathrm{~K}$ and atmospheric pressure are all negative. The minimum $\mathrm{V}^{\mathrm{E}}$ value obtained from eq 5 for each ternary system is located on the $V^{E}$ curve of the binary water + methanol $\left(x_{1}=0.4980, \mathrm{VE}=-1.013\right.$ $\mathrm{cm}^{3} \mathrm{~mol}^{-1}$ ). The $\Delta \eta$ values are all positive with a maximum 
on the binary water + methanol $\left(\mathrm{x}_{1}=0.6893, \Delta \eta=0.665\right.$ $\mathrm{mPa}$ s).

The binary $\mathrm{VE}$ data as well as the ternary ones were correlated using only three parameters in the RedlichKister polynomials, whereas, for the correlation of the binary $\Delta \eta$ data, even two coefficients were enough for a good fitting.

Since we have measured densities in the whole miscibility region including the proximity of the binodal curve, we have calculated the density values for this curve using the eqs 1,4 , and 5 . The aim of this procedure was to compare our calculated densities with the experimental data of Rao and Rao. ${ }^{1}$ We found that their data are systematically higher than our calculated values, although the mean percentage deviation is $0.5 \%$. In our opinion, this fact is due to the high density of the water used in their experiments, which value is not mentioned in their work.

The viscosity is a very important property in the design of liquid-liquid separation equipments. Equations 3-5 can be used to calculate the viscosities of the equilibrium phases.

\section{Literature Cited}

(1) Rao, R. J .; Rao, C. V. Ternary Liquid Equilibria: MethanolWater-Esters. J. Appl. Chem. 1957, 7, 435-439.

(2) Rao, R. J.; Rao, C. V. Ternary Liquid Equilibria Systems: N-Propanol-Water-Esters. J. Appl. Chem. 1959, 9, 69-73.

(3) Natividade, N. A. T.; Ferreira, A. G. M.; Fonseca, I. M. A. Densities and Excess Molar Volumes of Water + Propyl Acetate + Propan-1-ol and its Constituent Binaries at 303.15 K. J . Chem. Eng. Data 1997, 42, 1232-1234.

(4) Dizechi, M.; Marschall, E. Viscosity of Some Binary and Ternary Liquid Mixtures. J . Chem. Eng. Data 1982, 27, 358-363.

(5) Wilhoit, R. C.; Zwolinski, B. J. Physical and Thermodynamic Properties of Aliphatic Alcohols. J . Phys. Chem. Ref. Data 1973, 2, suppl 1.

(6) Pikkarainen, L. Densities and Viscosities of Binary Mixtures of $\mathrm{N}, \mathrm{N}$-Dimethylacetamide with Aliphatic Alcohols. J . Chem. Eng. Data 1983, 28, 344-347.
(7) Krishnam, K. M.; Raman, G. K. Excess Volumes and Speed of Sound of Ternary Mixtures of 2- Metoxyethanol (1) + Butyl Acetate (2) + Aromatic Hydrocarbons (3) at $303.15 \mathrm{~K}$. J . Chem. Eng. Data 1995, 40, 128-131.

(8) Kestin, J.; Sokol ov, M.; Wakeham, W. A. Viscosity of Liquid Water in the Range $-8^{\circ} \mathrm{C}$ to $150^{\circ} \mathrm{C}$. J . Phys. Chem. Ref. Data 1978, 7 , 941-948.

(9) Aralaguppi, M. I.; J adar, C. V.; Aminabhavi, T. M. Density, Viscosity, Refractive Index, and Speed of Sound in Binary Mixtures of Acrylonitrile with Methanol, Ethanol, Propan-1-ol, Butan-1-ol, Pentan-1-ol, Hexan-1-ol, Heptan-1-ol, and Butan-2ol. J . Chem. Eng. Data 1999, 44, 216-221.

(10) Aminabhavi, T. M.; Patil, V. B. Density, Viscosity, and Speed of Sound in Binary Mixtures of 1-Chloronaphthalene with Methanol, Ethanol, Propan-1-ol, Butan-1-ol, Pentan-1-ol, and Hexan-1-ol in the Temperature Range (298.15-308.15) K.J . Chem. Eng. Data 1998, 43, 504-508.

(11) Liu, C. Y.; Ku, H. C.; Tu, C. H. Densities and Viscosities of Five Alkyl Esters with Nitroethane Systems at $(293.15,303.15$, and 313.15) K.J . Chem. Eng. Data 1999, 44, 360-364.

(12) Aralaguppi, M. I.; J adar, C. V.; Aminabhavi, T. M. Density, Viscosity, Refractive Index and Speed of Sound in Binary Mixtures of 2-Chloroethanol with Methyl Acetate, Ethyl Acetate, N-Propyl Acetate, and N-Butyl Acetate. J . Chem. Eng. Data 1999, $44,441-445$.

(13) Spanedda, A.; Lepori, L.; Matteoli, E. Volumes of Mixing of Ethers with Tetrachloromethane at 298.15 K. Fluid Phase Equilib. 1991 69, 209-222.

(14) Benson, G. C.; Kiyohara, O. Thermodynamics of Aqueous Mixtures of Nonelectolytes. I. Excess Volumes of Water-n-Alcoho Mixtures at Several Temperatures. J . Solution Chem. 1980, 9 (10), 791-804.

(15) Redlich, O.; Kister, A. Algebraic Representation of Thermodynamic Properties and the Classification of Solutions. Ind. Eng Chem. 1948, 40, 345-348.

(16) Noda, K.; Ohashi, M.; I shida, K. Viscosities and Densities at 298.15 K for Mixtures of Methanol, Acetone, and Water. J . Chem. Eng. Data 1982, 27, 326-328.

(17) Cibulka, I. Estimation of Excess Volume and Density of Ternary Liquid Mixtures of Nonelectrolytes from Binary Data. Collect. Czech. Commun. 1982, 47, 1414-1419.

Received for review March 15, 2000. Accepted J une 19, 2000.

J E000085] 